\title{
MACROSCOPIC CHARACTERISTICS OF PALM OIL AND PALM OIL METHYL ESTER USING DIMENSIONLESS ANALYSIS
}

\author{
JAYAKAR, J*; ELUMALAI, P V ${ }^{\star *}$; ANNAMALAI, $\mathrm{K}^{\star *}$; MAILAINATHAN, M*; DHINESH, $\mathrm{B}^{\ddagger \ddagger}$ \\ and HARIKRISHNAN, G*
}

\begin{abstract}
The spray characteristics of fuels greatly influence the emissions from diesel engines. Spray development plays a vital role in improving the combustion and emission characteristics of fuels because it directly affects the air-fuel mixture formation. The spray characteristics of fuels depend mainly on the fuel injection process, fuel density, fuel viscosity, ambient pressure, and temperature. Among these, the effect of fuel injection pressure and fuel viscosity is a very important parameter directly affecting spray structures. This study investigates the effects of viscosity of fuel on pre-heating. The spray characteristics such as spray angle and spray tip penetration in a constant volume chamber under non-evaporating conditions are carried out by Mie scattering techniques and using Image J software. The Weber number, Reynolds number, and air to fluid density ratio dimensionless numbers were used to capture the primary forces including the inertia, surface tension, and aerodynamics. The experiments were carried out for different pre-heat temperatures. For the fuels and temperature-pressure conditions evaluated, the Weber number varies from 3000 to 120 000, the Reynolds number varies from 10000 to 63 000. The result of the macro analysis shows that an increase in the fuel temperature leads to a decrease in viscosity and density, thereby increasing the spray tip penetration.
\end{abstract}

Keywords: spray tip penetration, spray cone angle, palm oil, palm oil methyl ester, Reynolds number, Weber number.

Date received: 5 January 2018; Sent for revision: 2 February 2018; Received in final form: 9 July 2018; Accepted: 23 July 2018.

\section{INTRODUCTION}

In our everyday life, the car plays a dominating part (Dhinesh et al., 2016a). The inward burning engine has turned into a critical piece of our

* Department of Mechanical Engineering,

Dhanalakshmi College of Engineering, Chennai 601301, Tamil Nadu, India.

** Department of Automobile Engineering,

Madras Institute of Technology Campus, Anna University,

Chennai 600044, Tamil Nadu, India.

E-mail: elumalaimech89@gmail.com

‡ Department of Mechanical Engineering, Velammal Engineering College, Chennai 600066, Tamil Nadu, India.

\# Department of Mechanical Engineering, Mepco Schlenk Engineering College, Virudhunagar 626005, Tamil Nadu, India. everyday life (Dhinesh et al., 2016b). The increase in demand for fossil fuels has led to price increase; efficient methods are formulated for the utilisation of such fuel resource. The injection of fuel plays a vital role in increasing the efficiency of the engine. Expanding the number of car vehicles on the streets brings about twin issues, to be specific, the quick exhaustion of the regular non-renewable energy sources and the natural contamination caused by lethal outflow (Isaac Joshuaramesh Lalvani et al., 2015). The improvements in technology in recent times have made it possible to characterise the injection process (Krishnamoorthy et al., 2018). Those nations which import petroleum derivatives from other nations for their current financial development and advance are much stressed over 
their quick consumption and the void, it may make in case of our not having the capacity to locate an appropriate option fuel (Dhinesh et al., 2016c). In any case, the quick consumption of petroleum product has been making incredible stress in all countries (Dhinesh et al., 2018a). The purpose of these studies focuses on the achievements of a perfect mixture of the working and active fluids which result in the optimum combustion and therefore in the improvement of engine's capabilities (Chang Sik and Sung Wook 2002).

The biodiesel which can be used as an alternative fuel in the diesel engine, is made from a renewable biological resource such as vegetable oils and animal facts. Be that as it may, the main objections with biodiesel fuel concern $\mathrm{NO}_{x}$ and particulate emissions. These concerns ought to be legitimately tended to before executing down to earth applications (Annamalai et al., 2016). The real toxins from the diesel motors are $\mathrm{NO}_{x}$ (Parthasarathy et al., 2015). It is bio-degradable, nontoxic and possesses low emission profiles (Elumalai et al., 2018). Among them, the transesterification process includes the nearness of triglycerides from vegetable oil and animal fat blended with liquor or methanol and impetus to deliver tri-hydroxy liquor and mono-antacid ester (Lingesan et al., 2018). Many researchers have studied on the combustion and emission characteristic of biodiesel. On the contrary, detail studies of injection and spray atomisation characteristic are less frequent in literature, despite their fundamental nature.

In this work, spray atomisation was studied near the nozzle tip to examine the effects of fuel density and viscosity on the pre-heating of the biodiesel fuels (palm oil methyl ester, palm oil) (Santhanakrishana et al., 2017). Spray characteristics such as spray tip penetration and spray cone angle in a constant volume spray chamber under nonevaporating condition are carried out by Miescattering technique and using Image J software the dimensionless number such as Reynolds number, Weber number, and air to liquid density ratio is used for dimensionless analysis. These were used to capture primary forces including the inertia surface tension and viscous force (Xiangang et al., 2010). Spray penetration is defined as the length from the nozzle tip to the tip of the spray. Spray cone angle is defined as the angle between two lines connecting the nozzle tip and two half penetrations points on the spray boundary (Dent et al., 1971). Thus, non-dimensionless analysis was carried out by logarithmic calculation and dimensionless correlations are found for generating generic spray model.

\section{Experimental Set-up}

The experimental set-up for investigating the biodiesel sprays is outlined in Figure 1. The fuel is pre-heated by the redwood viscometer. The fuel is supplied from the fuel tank to the fuel injector by using a motor driven pump. The fuel injector injects fuel at a pressure of 200 bar (Masjuki et al., 1995). The fuel injector used is a mechanical injector with a single hole nozzle. The hole diameter is $0.231 \mathrm{~m}$ and the length to diameter office is $2 \mathrm{~mm}$. Using this spray injection system, the fuel was injected into the glass chamber $(40 * 40 * 5 \mathrm{~cm})$ and the spray was captured with a high-speed digital camera (Sony DSC-HX 1model). The pressure inside the chamber is 1 atmosphere and the temperature is $27^{\circ} \mathrm{C}-30^{\circ} \mathrm{C}$ (Payri et al., 2009a,b). Two sides of the chamber are transparent to make the inside observable. The macroscopic characteristic such as spray cone angle and spray penetration were measured from the image captured by the high-speed digital camera. Table 1 shows the experimental set up specification for spray analysis.

\section{TABLE 1. EXPERIMENTAL CONDITION}

\begin{tabular}{lc}
\hline Injection parameters & Quantity \\
Chamber pressure (bar) & 1.013 \\
Chamber temperature $(\mathrm{k})$ & 300 \\
Nozzle diameter (mm) & 0.231 \\
Injection pressure (bar) & 200 \\
Pre-heat fuel temperature $\left({ }^{\circ} \mathrm{C}\right)$ & $50,60,70,80,90$
\end{tabular}

\section{MATERIALS AND METHOD}

\section{Palm Oil Methyl Esther}

Unrefined palm oil extracted from palm seeds more often than not display high consistency making them unsatisfactory to be utilised as a fuel for persistent running. Hence, a procedure called transesterification is performed in order to diminish the consistency by treating the unrefined palm oil with alcohols (usually ethanol or methanol) where in glycerol is a by-product which must be isolated (Ejilah et al., 2010). Transesterification oil or fat into methyl esters transesterified palm methyl ester was purchased from Rasha Petroleum Limited and the diesel fuel utilised as standard was obtained from a Bharat Petroleum oil station in Chennai, India (Dhinesh et al., 2018b). The different physical and substance properties of palm ethyl ester are contrasted with that of traditional petro diesel and the descriptions of palm methyl ester's properties are noted underneath in Table 2.

\section{Uncertainty Percentage}

The uncertainty level of the test directed has been ascertained by the square foundation of the entirety of squares, the estimations of speed, pressure, Reynolds number, Weber number, spray penetration, spray cone angle. The vulnerability 


\begin{tabular}{lcc}
$\begin{array}{c}\text { TABLE 2. PROPERTIES OF PALM OIL METHYL ESTER } \\
\text { (POME) AND PURE PALM OIL }\end{array}$ \\
\hline Property & POME & Pure palm oil \\
\hline Specific gravity @ $20^{\circ} \mathrm{C}$ & 0.880 & 0.920 \\
Heating value (MJ kg $)^{-1}$ & 38.6 & 41 \\
Acid value $\left(\mathrm{mg} \mathrm{KOH} \mathrm{g}^{-1}\right)$ & 0.49 & 0.52 \\
Density (kg m $\left.{ }^{-3}\right)$ & 873 & 893 \\
Carbon weight $(\%)$ & 76.2 & 78 \\
Hydrogen weight $(\%)$ & 12.6 & 12.7 \\
Viscosity (cp) 40 & 4.41 & 5.42 \\
Flash point $\left({ }^{\circ} \mathrm{C}\right)$ & 144 & 190 \\
\hline
\end{tabular}

which can be represented by three dimensionless numbers, Weber number, Reynolds number, and the air-to-liquid density ratio. Sprays with similar magnitudes of Weber number, Reynolds number, and air-to-liquid density ratio have similar structure and characteristics (Payri et al., 2009b). The fuel used for the experiments are palm oil methyl ester and palm oil. The most important physical properties of fuel namely density and kinematic viscosity were measured both by the properties are very critical and affect the spray characteristics. Images

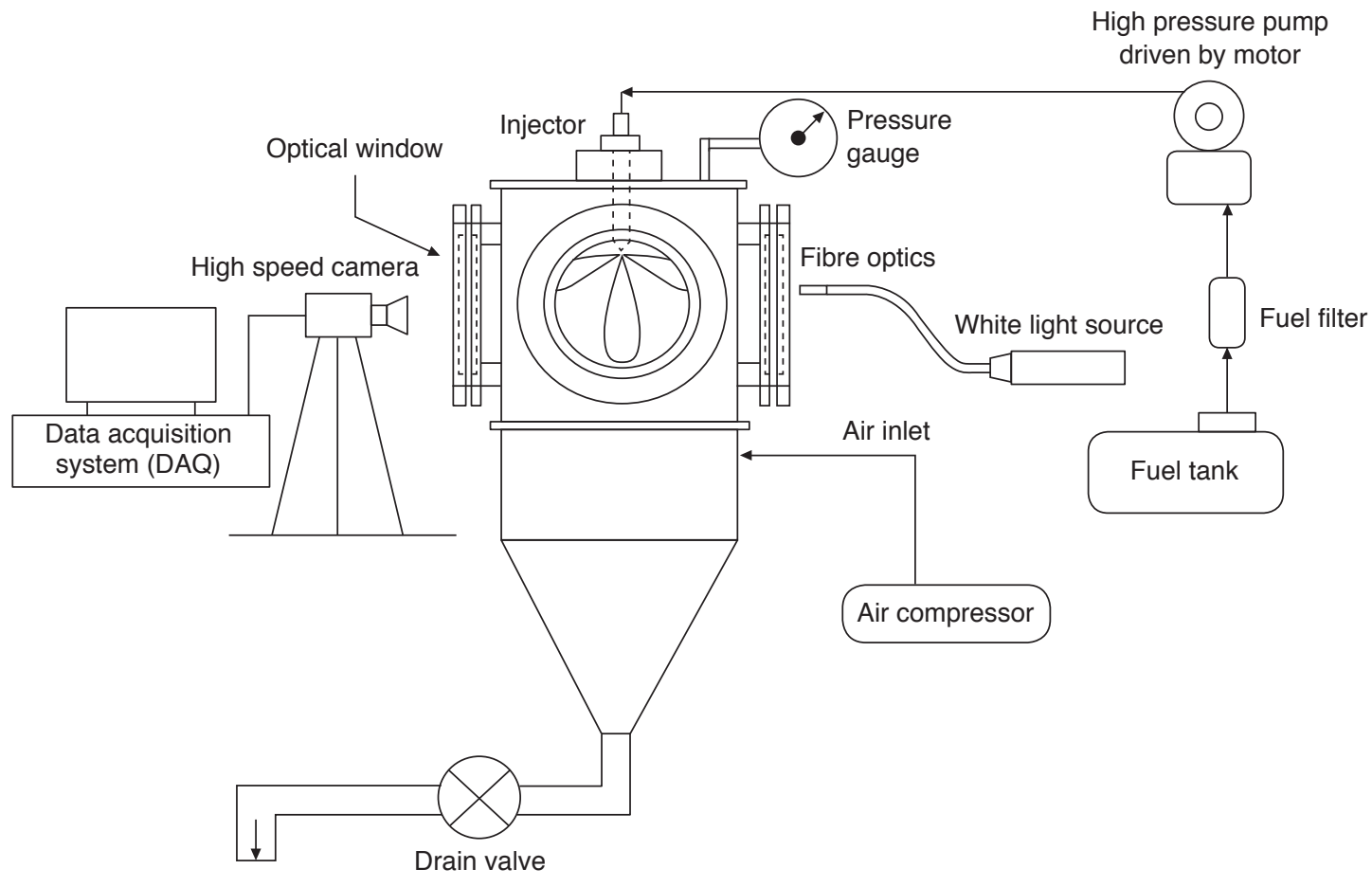

Figure 1. Experimental set-up.

for the aggregate investigation led $2.02 \%$ which is concurring with the prior discovering in Table 3.

\section{RESULT AND DISCUSSION}

The variation of Reynolds and Weber numbers for spraying velocity is shown in Figure 2. Spray characteristics are primarily dependent on the competition among the four major forces acting on a liquid jet; the inertia force, the viscous force, the surface tension force and the air drag force,

\section{TABLE 3. UNCERTAINTY ANALYSIS}

\begin{tabular}{lc}
\hline Parameters & Percentage \\
\hline Weber number & 1.0 \\
Reynolds number & 0.9 \\
Spray cone angle & 0.8 \\
Spray penetration & 1.2 \\
Velocity & 0.98 \\
\hline
\end{tabular}

are recorded for every change in pre-heated fuel temperature (Delacourt et al., 2005). This study focuses on the high-speed fuel jet break up near the injector tip. The macroscopic characteristics such as spray cone angle, spray tip penetration was studied experimentally from the images taken by the high-speed digital camera. Strong correlations between the macroscopic spray structure (spray penetration and spray cone angle) and Weber number are observed which primarily describes, the importance of the inertia effect as surface tension effect was relatively small for the given test conditions. When the Reynolds number is above 22 570, the effect of inertia force is significantly greater than that of viscous force; the Reynolds number effect on spray penetration and spray cone angle are negligible. When Reynolds number is below 22 570, the viscous effect plays a more important role, especially for Reynolds numbers below 10000 . For this investigation, the Weber number and air-to-liquid density ratio have a much 


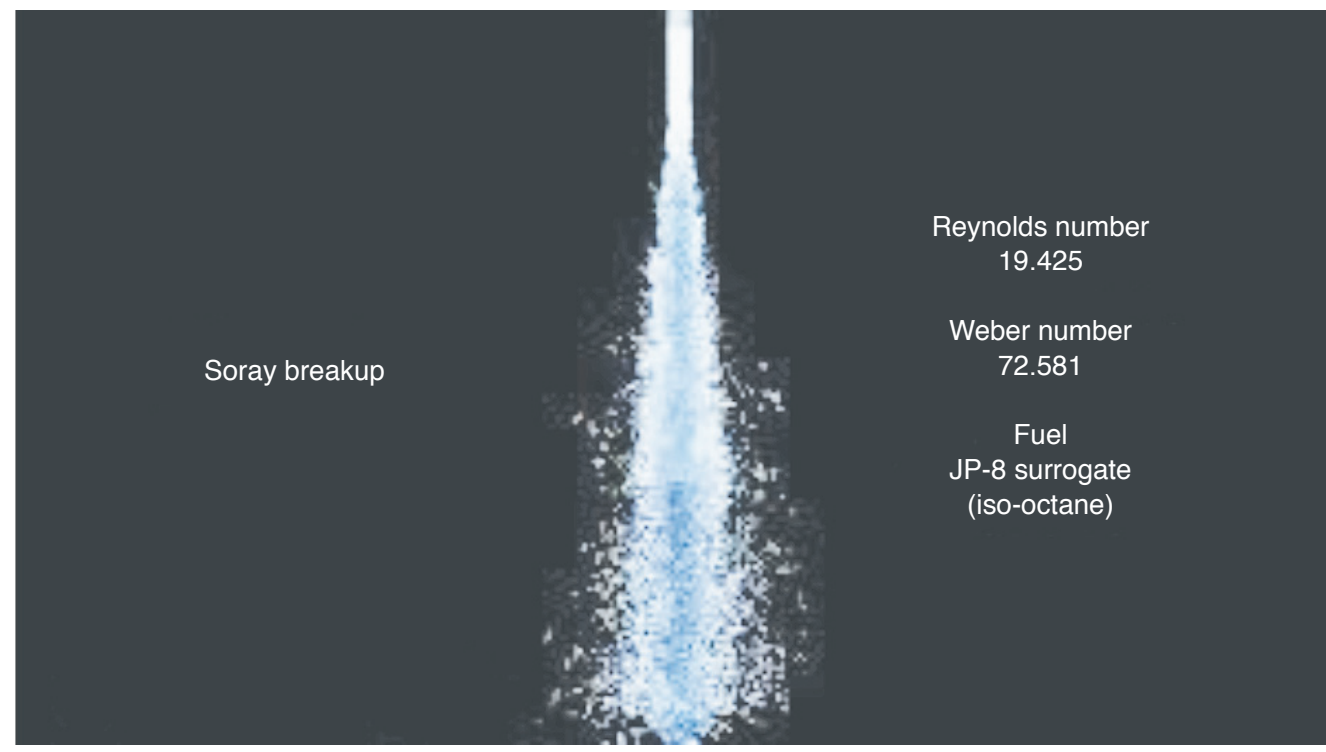

Figure 2. Spraying velocity.

more profound effect on the spray penetration and spray cone angle compared to the Reynolds number contribution. The inertia force and air drag force are more important factors compared to the viscous force and surface tension force. Thus, yielded a dimensionless correlation for the spray penetration, spray cone angle, thereby generating a new generic spray model.

\section{Weber and Reynolds Numbers Effect on Macroscopic Spray Structure}

The Reynolds number versus spray tip penetration is shown in Figure 3. For the fuel and temperature-pressure conditions evaluated, the Weber number varies from 3000 to 120000 and the Reynolds number varies from 10000 to 63000 . Lower Weber number and Reynolds number conditions provide characteristics of small inertia forces due to low injection pressure with large viscous force due to low temperature together; these provide a relatively small spray momentum where a weak interaction between the liquid and the surrounding air is anticipated. The spray cone angle exhibits a low penetration with a narrow spray cone angle width, consistent with Rayleigh break up a theory. The Reynolds number versus spray cone angle is shown in Figure 4.

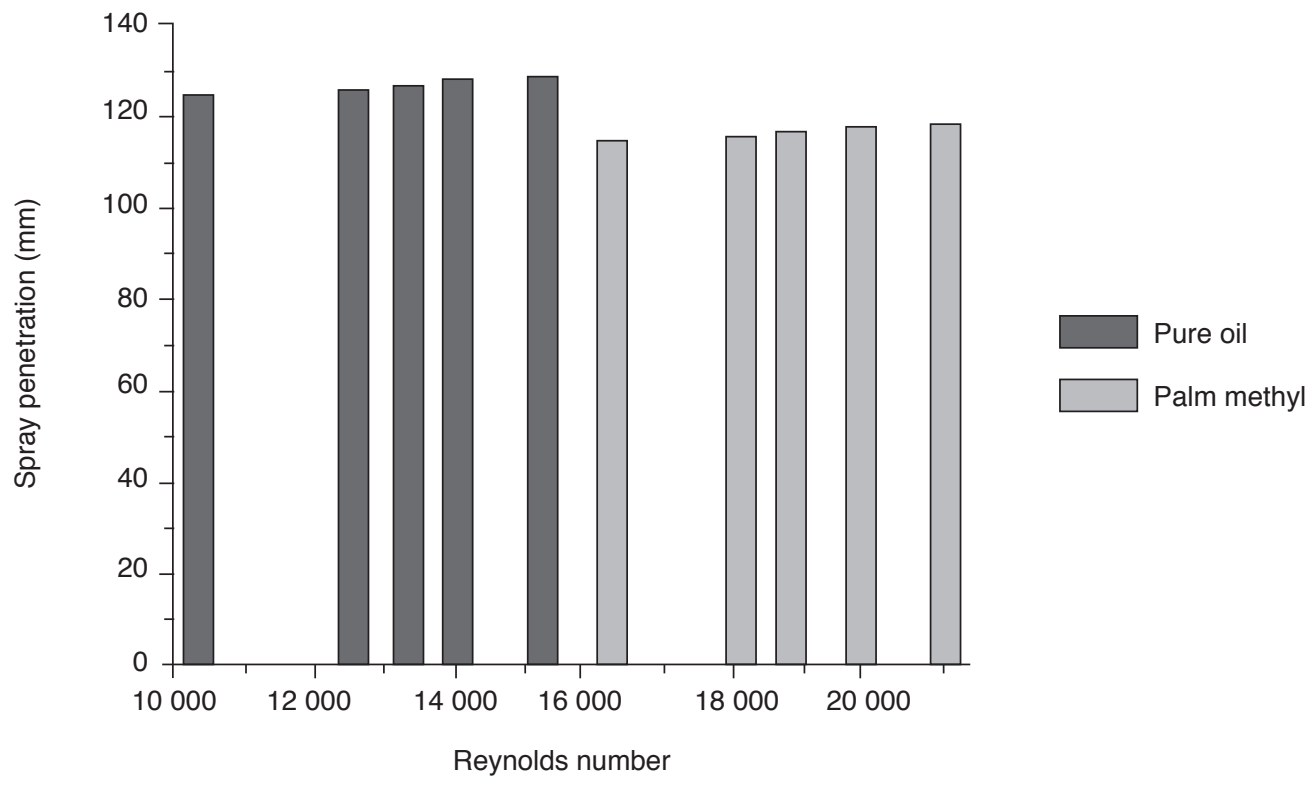

Figure 3. Reynolds number vs. spray tip penetration. 


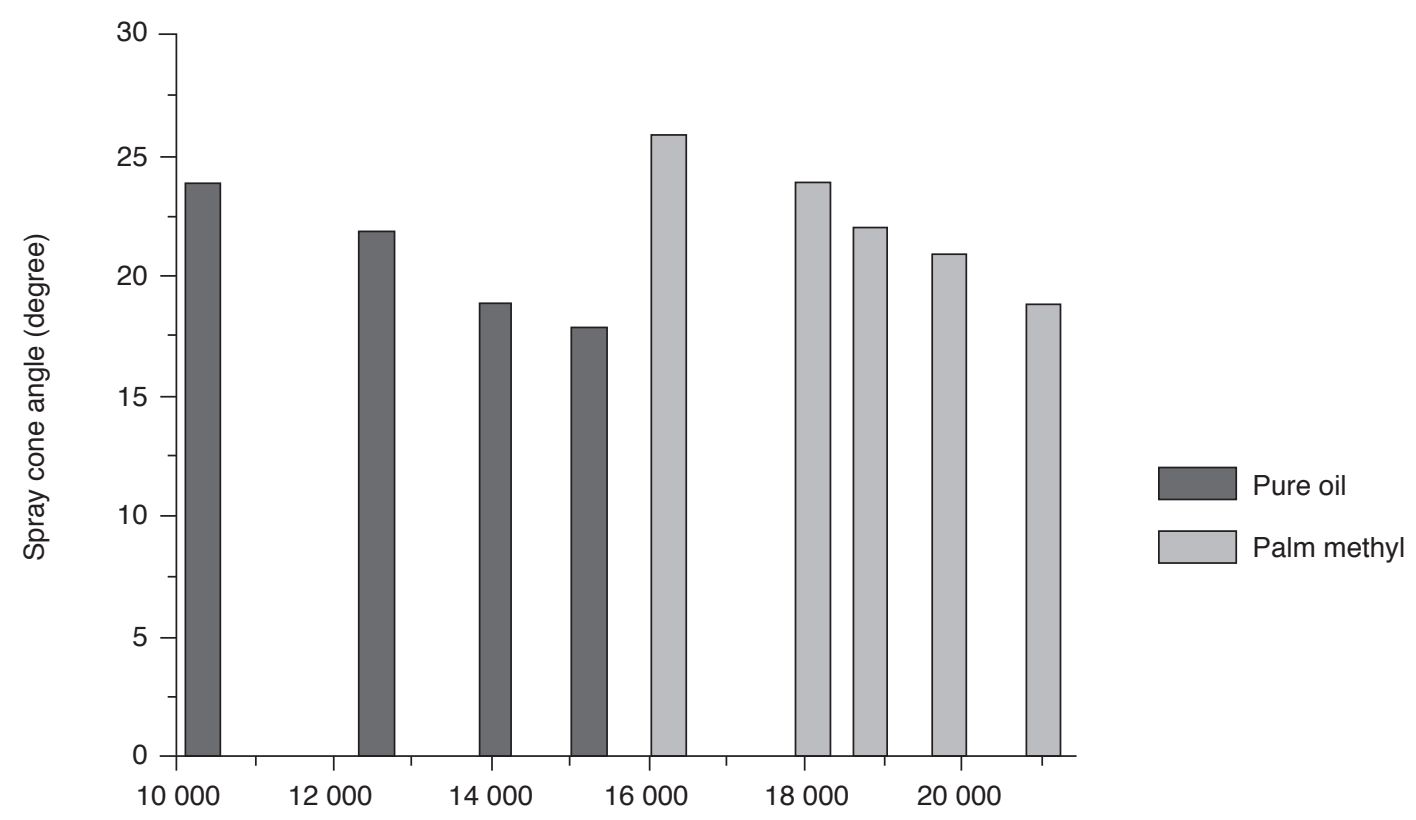

Figure 4. Reynolds number vs. spray cone angle.

\section{Correlation between Spray Macroscopic Characteristics and Dimensionless Number}

The Weber number versus spray tip penetration is shown in Figure 5. In general, these macroscopic spray parameter increase in a nearly linear fashion with increasing the Reynolds number. This behaviour is attributed to the viscosity change as the observation is made assuming constant injection pressure and air-to-liquid density ratio. Due to preheating of the fuel the viscosity and density of the fuel reduce thus the spray tip penetration increase and the spray cone angle (Michele et al., 2011). The Weber number versus spray cone angle is shown in Figure 6.

The spray tip penetration and spray cone angle versus Weber number give a strong correlation such as:

$$
\begin{aligned}
& \mathrm{S} \alpha(\mathrm{We})^{0.509} \\
& \mathrm{~S} \alpha(\mathrm{We})^{0.486} \\
& \theta \alpha(\mathrm{We})^{0.309} \\
& \theta \alpha(\mathrm{We})^{0.347}
\end{aligned}
$$

Equation 1

Equation 2

Equation 3

Equation 4

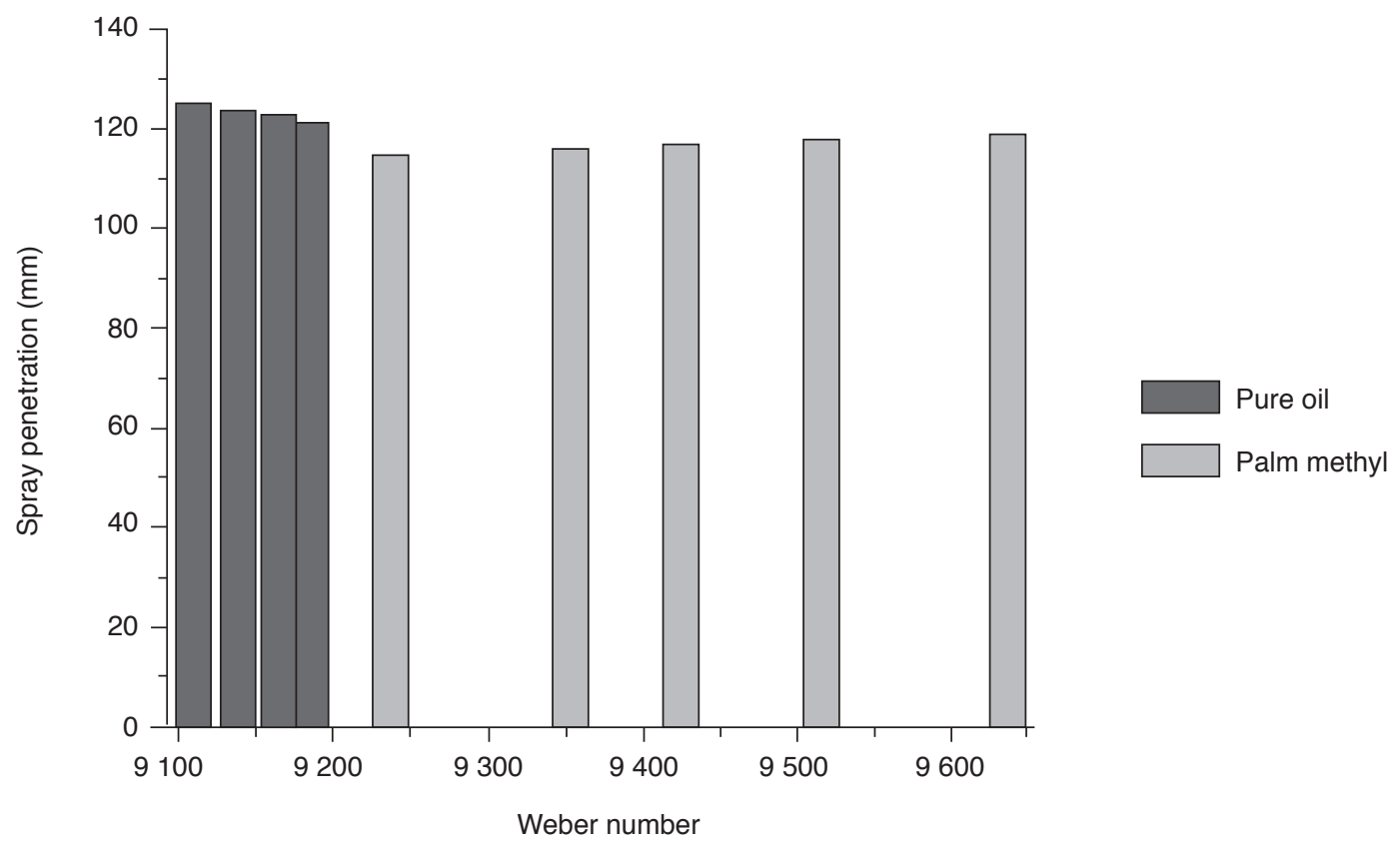

Figure 5. Weber number vs. spray tip penetration. 


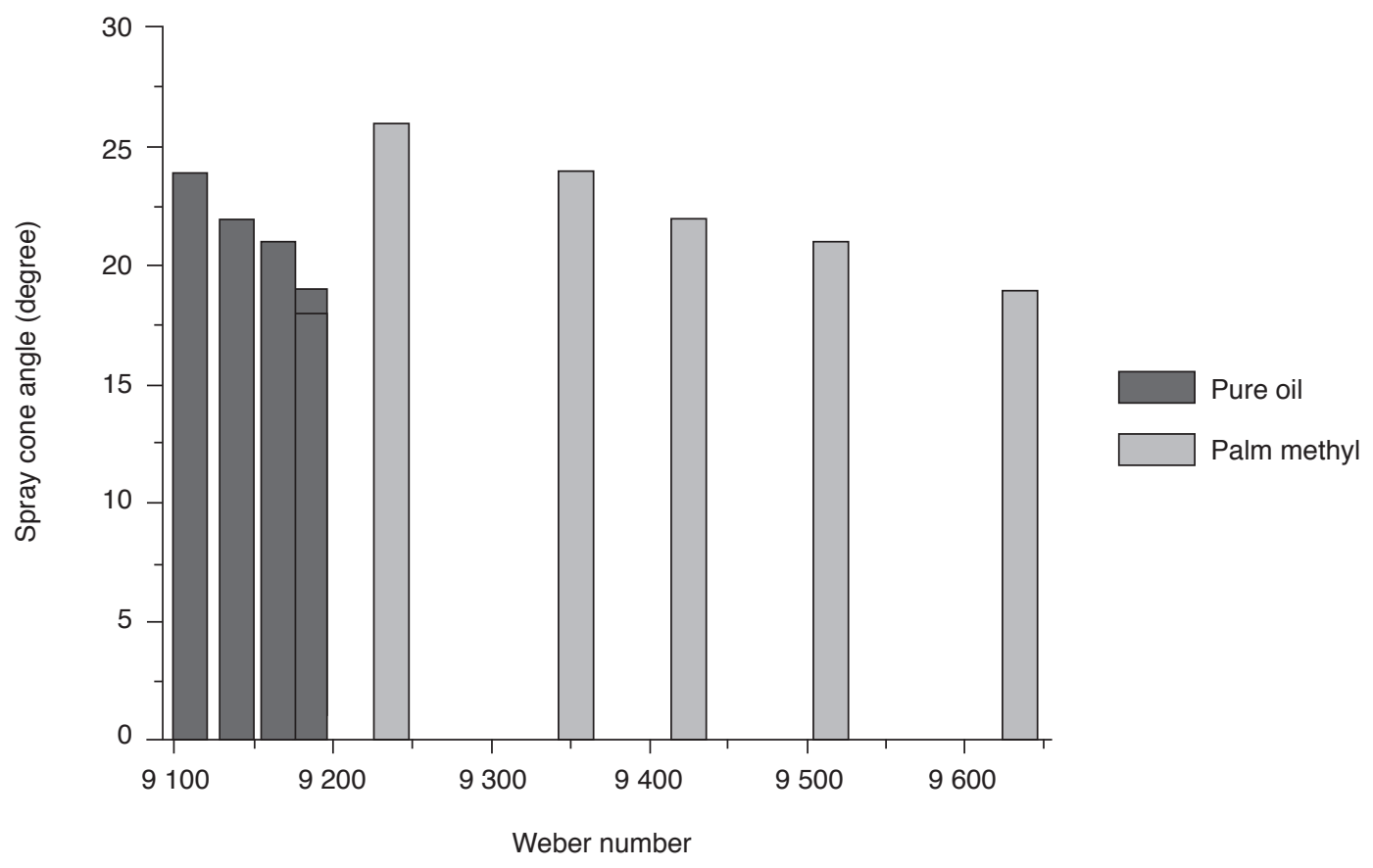

Figure 6. Weber number vs. spray cone angle.

The domain effect of the air-to-liquid density ratio on the spray penetration and spray cone angle which is provided by the following equation.

$$
\begin{aligned}
& \mathrm{S} \alpha(\mathrm{\varrho a} / \mathrm{\varrho l})^{-0.704} \\
& \mathrm{~S} \alpha(\mathrm{\varrho} / \mathrm{\varrho l})^{-0.668} \\
& \theta \alpha(\mathrm{\varrho} / \mathrm{\varrho l})^{-0.427} \\
& \theta \alpha(\mathrm{\varrho} / \mathrm{\varrho l})^{-0.476}
\end{aligned}
$$

Correlations for palm oil $(1,3,5,7,9,11)$ and palm oil methyl ester $(2,4,6,8,10,12)$ were developed to comprehend the effects of all three dimensionless numbers on spray penetration and spray angle.

$$
\begin{gathered}
\mathrm{S}=0.984\left(\mathrm{Q}_{\mathrm{a}} / \mathrm{Q}_{1}\right)^{-0.704} \cdot(\mathrm{We})^{0.509} \cdot(\mathrm{Re})^{-0.493}, \operatorname{Re}<13215 \\
\text { Equation } 9 \\
\mathrm{~S}=0.984\left(\mathrm{Q}_{\mathrm{a}} / \mathrm{Q}_{\mathrm{l}}\right)^{-0.668} \cdot(\mathrm{We})^{0.486} \cdot(\mathrm{Re})^{-0.455}, \mathrm{Re}<22570 \\
\text { Equation } 10 \\
\theta=1.034\left(\mathrm{Q}_{\mathrm{a}} / \mathrm{Q}_{1}\right)^{-0.427} \cdot(\mathrm{We})^{0.309} \cdot(\operatorname{Re})^{-0.293}, \operatorname{Re}<13215 \\
\text { Equation } 11 \\
\theta=1.018\left(\mathrm{Q}_{\mathrm{a}} / \mathrm{Q}_{1}\right)^{-0.476} \cdot(\mathrm{We})^{0.347} \cdot(\mathrm{Re})^{-0.325}, \operatorname{Re}<22570 \\
\text { Equation } 12
\end{gathered}
$$

\section{CONCLUSION}

A dimensionless analysis was applied to constant the volume spray chamber to investigate the macroscopic characteristics of a single hole. Weber number, Reynolds number, and air-to-liquid density ratio were used to represent the primary effects on spray. Spray images were generated using the Mie-scattering technique. The experiments were carried out for different pre-heat temperature. For

the fuels and temperature-pressure conditions evaluated, the Weber number varies from 3000 to 120 000, the Reynolds number varies from 10000 to 63000 , the correlations between these dimensionless numbers, spray penetration and spray cone angle provide a fundamental understanding of physical characteristics. The results yield formulations for spray penetration and spray cone angle. The good correlations between these three dimensionless numbers and spray macroscopic characteristics have yielded a set of general formulations. These formulations provide important insight into the spray break-up and atomisation processes, and could be used to generate generic spray models which express the physical mechanism explicitly, independent of the test conditions and fuel type. By doing this experiments, we can find better atomisation range for all the biodiesel fuel.

\section{ACKNOWLEDGEMENT}

We thank the management of Sri Venkateswara College of Engineering and Sakthi Pressure Vessels Ltd, Chennai, India for providing us with the necessary experimental set-up to perform this research work.

\section{REFERENCES}

ANNAMALAI, M and DHINESH, B (2016). An assessment on performance, combustion and emission behavior of a diesel engine powered by 
ceria nanoparticle blended emulsified biofuel. Energy Conversion and Management, 123: 372-380. http: / / dx.doi.org/10.1016/j.enconman.2016.06.062

CHANG SIK, L and SUNG WOOK, P (2002). An experimental and numerical study on fuel atomization characteristics of high-pressure diesel injection sprays. Fuel, 81: 2417-2423.

DELACOURT, E; DESMET, B and BESSON, B (2005). Characterisation of very high injection pressure diesels prays using digital imaging techniques. Fuel, 84: 859-867.

DENT, J (1971). Basis for the comparison of various experimental methods for studying spray penetration. SAE Trans, 80: 71057.

DHINESH, B; ISAAC JOSHUARAMESH LALVANI, $\mathrm{J}$; PARTHASARATHY, $\mathrm{M}$ and ANNAMALAI, K (2016a). An assessment on performance, emission and combustion characteristics of single cylinder diesel engine powered by Cymbopogon flexuosus biofuel. Energy Conversion and Management, 117: 466-474. http://dx.doi.org/10.1016/j. enconman.2016.03.049

DHINESH, B; NIRUBAN BHARATHI, R; ISAAC JOSHUARAMESH LALVANI, J; PARTHASARATHY, $M$ and ANNAMALAI, K (2016b). An experimental analysis on the influence of fuel borne additives on the single cylinder diesel engine powered by Cymbopogon flexuosus biofuel. J. Energy Institute, 90: 634-645. http://dx.doi. org/10.1016/j.joei.2016.04.010

DHINESH, B; ARUMUGAM, S; LINGESAN, S; CHELLAKUMAR, J S and MANI, A (2016c). Studies on the influence of combustion bowl modification for the operation of Cymbopogon flexuosus biofuel based diesel blends in a DI diesel engine. Applied Thermal Engineering, 112: 627-637. http://dx.doi. org/10.1016/j.applthermaleng. 2016.10.117

DHINESH, B (2018a). A numerical study on the effect of various combustion bowl parameters on the performance, combustion, and emission behavior on a single cylinder diesel engine. Environmental Science and Pollution Research, 25: 2273-2284.

DHINESH, B and ANNAMALAI, M (2018b). A study on performance, combustion and emission behavior of diesel engine powered by novel nano nerium oleander biofuel. J. Production, 196: 74-83. DOI: 10.1016/j.jclepro.2018.06.002.

ELUMALAI, P V; ANNAMLAI, K; LINGESAN, S; ARULARASU, $S$ and APPU RAJA, S (2018). Experimental investigation on lemon grass oil water emulsion in low heat rejection direct ignition diesel engine. J. Testing and Evaluation. In press. DOI:10.1520/JTE20170357.

EJILAH, I R; ASERE, A A; ADISA, A B and EJILA, A (2010). The effect of diesel fuel-jatropha curcas oil methyl ester blend on the performance of a variable speed compression ignition engine. J. Agricultural Engineering, 1: 80-85.

ISAAC JOSHUARAMESH LALVANI, J; PARTHASARATHY, $\mathrm{M}$; DHINESH, B and ANNAMALAI, K (2015). Pooled effect of injection pressure and turbulence inducer piston on performance, combustion, and emission characteristics of a DI diesel engine powered with biodiesel blend. Ecotoxicology and Environmental Safety, 134: 336-343. http://dx.doi.org/10.1016/j. ecoenv.2015.08.020

KRISHNAMOORTHY, R; ANNAMALAI, K; LINEGESAN, S; DHINESH, B and PAUL JAMES, T (2018). An assessment of combustion, performance characteristics and emission control strategy by adding anti-oxidant additive in emulsified fuel. Atmospheric Pollution Research. https://doi. org/10.1016/j.apr.2018.02.007.

LINGESAN, S; PARATHASARATHY, M; DHINESH, B and KRISHNAMOORTHY, R (2018). Novel Garcinia gummi-gutta methyl ester (GGME) as a potential alternative feedstock for existing unmodified DI diesel engine. Renewable Energy, 125: 568-577.

MICHELE, B and CARLO NAZARENO GRIMALDI (2011). Numerical analysis of injector flow and spray characteristics from diesel injectors using fossil fuels and biodiesels fuel. Applied Energy, 97: 656-666.

MASJUKI, H; ABDULMUIN, M Z and SII, H S (1995). Investigation of palm oil diesel emulsion as a fuel extender for diesel engine. J. Oil Palm Res. Special Issue: 79-91.

PARTHASARATHY, M; ISAAC JOSHUARAMESH LALVANI, J; DHINESH, B and ANNAMALAI, K (2015). Effect of hydrogen on ethanol-biodiesel blend on performance and emission characteristics of a direct injection diesel engine. Ecotoxicology and Environmental Safety, 134: 433-439. http://dx.doi. org/10.1016/j.ecoenv.2015.11.005

PAYRI, R; DESANTES, J M; SALVADAR, F J and MANIN, J (2009a). Influence on diesel injection characteristics and behavior using biodiesel fuels. Society of Automobile Engineers, 01: 0851.

PAYRI, R; DESANTES, J M; SALVADAR, F J and MANIN, J (2009b). Study of cavitations phenomena 
based on a technique for visualizing bubbles in a liquid pressured chamber. International J. Heat and Fluid Flow, 30: 768-777.

\section{SANTHANAKRISHANA}

RAMAKRISHNAN;

YUVARAJAN DEVARAJAN; ARULPRAKA

SAJOTHI MAHALINJAM and BEEMKUMAR

NAGAPPAN (2017). Emission analysis on diesel engine fueled with palm oil biodiesel and pentanol. J. Oil Palm Res. Vol. 29: 380-386.

XIANGANG WANG; ZUOHUA HUAN; OLAWOLE ABIOLA KUTI and WUZHANG KEIYA ISHIDA (2010). Experimental and analytical study on biodiesel and diesel spray characteristics under ultrahigh injection pressure. International J. Heat and Fluid Flow, 31: 659-666. 